\title{
Evaluation of Hydroalcoholic Extract of Convolvulus pluriculis (Shankapushpi) for Standardization by Colorimetric Method: A Preliminary Report
}

\author{
Gangadhara Swamy ${ }^{1}$ Rajendra Holla ${ }^{2}$ Suresh R. Rao ${ }^{1}$ \\ ${ }^{1}$ Department of Anatomy, Subbaiah Institute of Medical Sciences \\ and Research Center, Shivamogga, Karnataka, India \\ 2Department of Pharmacology, K. S. Hegde Medical Academy, \\ Deralakatte, Mangalore, Karnataka, India
}

J Health Allied Sci NU 2019;9:121-126

\begin{abstract}
Address for correspondence Suresh R. Rao, PhD, Department of Anatomy, Subbaiah Institute of Medical Sciences and Research Center, Shivamogga, Karnataka 577222, India (e-mail: s4chavan@yahoo.co.in).
\end{abstract}

\author{
Abstract \\ Keywords \\ - hydroalcoholic \\ - Convolvulus pluriculis \\ - phytochemical \\ analysis \\ - HPTLC
}

\begin{abstract}
Aim This study was aimed to evaluate the hydroalcoholic extract of Convolvulus pluricaulis (HACP) for standardization using colorimetric method.

Materials and Methods Establishment of standardization for the Ayurvedic formulations is most important for its chemical compounds, biological action, and its quality reassurance in production and manufacturing of traditional herbal medicines. As most of the drugs are standardized, drug companies are using substitute drugs instead of true drugs. So to make finest superiority drugs, it is necessary to validate the raw drugs. Observing the existing trend in mind, HACP was subjected to standardize procedures for the phytochemical tests. The separation of the bioactive substances from the HACP was performed using both manual methods and high-profile thin-layer chromatography (HPTLC).

Results From this study, it is revealed that the seed contains alkaloids, carbohydrates, steroids, tannins, terpenoid, and phenol which gave the medicine numerous therapeutic properties.

Conclusion The study was rapid, reproducible, and could be used for routine monitoring of various biological properties of HACP.
\end{abstract}

\section{Introduction}

The $80 \%$ rural population of a country is more tending toward traditional ways of treatment due to easy availability and cheaper cost. ${ }^{1}$ In the world, approximately 35,000 to 70,000 species of plant have been used at one time or another for medicinal, pharmaceuticals, and cosmetic. ${ }^{2}$ Convolvulus pluricaulis (C. pluricaulis) popularly known as Shankapushpi is one such herb that has been extensively investigated for its pharmacological and therapeutic effects. Its branches spread on the ground which are more than $30-\mathrm{cm}$ long. The flowers are blue/white in color and the leaves which are elliptic in shape are located at alternate positions with branches or flowers. The herb is commonly found throughout India. All the parts of the herb are known to possess therapeutic benefits. ${ }^{3}$ The plant contains alkaloid (shankhapushpine), volatile oil, flavonoids (kampferol derivatives), a phytosterol ( $\beta$-sitosterol), carbohydrates (glucose, rhamnose, and starch), ceryl alcohol, and scopoletin. ${ }^{4}$ The fresh plant contains volatile oils, fatty acids, fatty alcohols, and hydrocarbons, that is, myristic acid (30.9\%), palmitic acid (66.8\%), linoleic acid (2.3\%), and straight-chain hydrocarbon hexatriacontane. ${ }^{5}$

It is reported that it is traditionally used to treat nervous debility, insomnia, fatigue, fever, nervous debility, and loss of memory. It is a good remedy in bowel complaints like dysentery. C. pluricaulis is used as a one of the main ingredients in the brain tonics. The plant is reported to be a prominent memory enhancer and also a psychostimulant, tranquilizer and reduce mental tension. ${ }^{6,7}$ A phytochemical investigations on $C$. pluricaulis have been reported that an received

September 26, 2019

accepted after revision

November 21, 2019
DOI https://doi.org/

$10.1055 / \mathrm{s}-0039-3402085$

ISSN 2582-4287.
Copyright $@ 2019$ Nitte University

(Deemed to be University)
License terms

(1) (1) $\odot \circledast$ 
alkaloid (shankhpushpine), flavonoids, and inorganic salts (e.g., potassium chloride) were present and also two varieties of bases had been isolated viz base $\mathrm{A}\left(\mathrm{C}_{5} \mathrm{H}_{11} \mathrm{NO}_{2}\right)$ which depressed the blood pressure in an anesthetized dog and had temporary inhibitory action on pithed frog's heart. Base B $\left(\mathrm{C}_{5} \mathrm{H}_{9} \mathrm{NO}_{2}\right)$ had no significant pharmacological action. ${ }^{8}$

As the drug has numerous therapeutic properties and its uses in the field of medicine, one should be aware of its photochemistry also. So, to prepare the best quality C. pluricaulis drug, it is necessary to authenticate the raw drugs. Keeping the current trend in mind, C. pluricaulis was subjected to standardizing procedures. For the current study, genuinity indicating parameters for $C$. pluricaulis were derived.

\section{Materials and Methods}

\section{Plant Material}

The $C$. pluricaulis whole plant was collected from the Sri Dharmastala Ayurveda Medical College and Research Centre at Udupi in Karnataka, India. The plant material was stored in ambient conditions for further study.

\section{Preparation of Extracts}

The $C$. pluricaulis whole plant was dried in the shade and powdered in our research laboratory with the help of pulverizer. The hydroalcoholic extract of Convolvulus pluricaulis (HACP) was prepared by soaking $500 \mathrm{~g}$ of powder in $2 \mathrm{~L}$ of $50 \%$ ethanol and 50\% cold distilled water for 24 hours, filtered, and concentrated by evaporating on water bath till free from water. The extract has been stored in an airtight container under normal temperature. ${ }^{9}$

Phytochemical tests like tests for alkaloids, steroids, saponins, tannins, flavonoids, phenol, coumarins, triterpenoids, carboxylic acid, resin, quinine, and high-profile thin-layer chromatography (HPTLC) were performed as per the WHO (World Health Organization) guidelines, ${ }^{10}$ Ayurvedic Pharmacopoeia, ${ }^{11}$ and Indian Pharmacopoeia. ${ }^{12}$

\section{Preliminary Phytochemical Tests}

Tests for Alkaloids

a. Dragendroff's test: To a few mg of HACP extract dissolved in alcohol and few drops of acetic acid and Dragendroff's reagent was added, then shake well. An orange-red precipitate formed indicates the presence of alkaloids. ${ }^{13}$

b. Wagners's test: To a few mg of extract dissolved in acetic acid, a few drops of Wagner's reagent was added. A reddish-brown precipitate formed indicates the presence of alkaloids. ${ }^{14}$

c. Mayer's test: To a few mg of HACP extract dissolved in acetic acid and few drops of Mayer's reagent was added. A dull-white precipitate will be formed if the alkaloids are present. ${ }^{15}$

d. Hager's test: To a few mg of extract dissolved in acetic acid, $3 \mathrm{~mL}$ of Hager's reagent was added, the formation of a yellow precipitate indicates the presence of alkaloids. ${ }^{16}$

\section{Tests for Carbohydrates}

a. Molisch's test: To the HACP, along the sides of the test tube, $1 \mathrm{~mL}$ of $\alpha$-naphthol solution and concentrated (conc.) sulfuric acids were added along the sides of the test tube. If carbohydrates are present then a violet color formed at the junction of the two liquids. ${ }^{17}$

b. Fehling's test: Few mg of HACP was mixed with equal quantities of Fehling's solutions A and B. The mixture was warmed in a water bath. If carbohydrates are present, then the formation of a brick-red precipitate is seen. ${ }^{18}$

c. Benedict's test: To $5 \mathrm{~mL}$ of Benedict's reagent, a few mg of the extract was added, and boiled for 2 minutes and cooled. Formation of a red precipitate indicates the presence of carbohydrates. ${ }^{19}$

\section{Test for Steroids}

a. Libermann-Burchard test: To the extract was dissolved in chloroform, $1 \mathrm{~mL}$ of acetic acid and $1 \mathrm{~mL}$ of acetic anhydride were added, then heated on a water bath and cooled. Few drops of conc. sulfuric acid was added along the sides of the test tube. The appearance of a bluish-green color indicates the presence of steroids. ${ }^{20}$

b. Salkowski's test: The HACP was dissolved in chloroform and equal volume of conc. sulfuric acid was added. Formation of bluish-red to a cherry-red color in chloroform layer and green fluorescence in the acid layer indicates the presence of steroids. ${ }^{21}$

\section{Test for Saponins}

In a test tube containing $0.5 \mathrm{~mL}$ of extract, 5 to 10 drops of dilute $\mathrm{HCl}$ and $\mathrm{ZnCl}$ were added the solution was boiled for a few minutes. Presence of reddish-pink or dirty-brown color confirms flavonoid. ${ }^{22}$

\section{Test for tannins}

To the extract, a drops of dilute solution of ferric chloride $\left(\mathrm{FeCl}_{3}\right)$ were added, formation of dark-blue color shows the presence of tannins. ${ }^{23}$

\section{Test for Flavonoids}

Shinoda's test: in a test tube containing $0.5 \mathrm{~mL}$ of extract, 5 to 10 drops of dilute $\mathrm{HCl}$ and $\mathrm{ZnCl}$ were added to the solution and was boiled for a few minutes. Presence of reddish-pink or dirty-brown color confirms flavonoid. ${ }^{24}$

\section{Test for Phenol}

To HACP in alcohol, add two drops of alcoholic ferric chloride. Formation of blue to black indicates the presence of phenol. ${ }^{25}$

\section{Test for Coumarins}

To the extract in alcohol, a few drops of 2-N (normal) sodium hydroxide $(\mathrm{NaOH})$ solutions were added. Dark yellow color formation indicates the presence of coumarins. ${ }^{23}$ 


\section{Test for Triterpenoids}

The extract was warmed with tiny bits and a few drops of vinyl chloride. Formation of pink color indicates the presence of triterpenoids. ${ }^{26}$

\section{Test for Carboxylic Acid}

Extract dissolved in water is treated with sodium bicarbonate. Brisk effervescence indicates the presence of carboxylic acid. ${ }^{27}$

\section{Test for Resin}

Few mg of the sample was mixed with water and acetone. Turbidity indicates the presence of resin..$^{28}$

\section{Test for Quinine}

Few mg of HACP was treated with $0.5 \%$ of $\mathrm{NaOH}$. If quinine is present it gives deep coloration like pink, purple or red. ${ }^{26}$

\section{High-Profile Thin-Layer Chromatography}

Powdered sample of $1 \mathrm{~g}$ was dissolved in $10 \mathrm{~mL}$ ethanol and kept for cold percolation for 24 hours and filtered. Of the sample, 4, 8 , and $12 \mu \mathrm{L}$ were applied to a precoated silica gel F254 on aluminum plates to a bandwidth of $7 \mathrm{~mm}$ using Linomat 5 Thin Layer Chromatography (TLC) applicator. The plate was developed in $n$-butanol:acetic acid:water (4:1:1). The developed plates were visualized in short ultraviolet (UV), long UV, and then derivatised with vanillin sulfuric acid reagent and scanned under 254 , $366 \mathrm{~nm}$, and white light at $620 \mathrm{~nm}$. Retention factor $\left(\mathrm{R}_{\mathrm{f}}\right.$, the color of the spots and densitometric scan were recorded. ${ }^{29}$

\section{Results and Discussion}

In the present experiment, it has been found that qualitative analysis of phytochemical compounds obtained in HACP by colorimetry ( - Tables 1 and $\mathbf{2}$ ), photo documentation ( - Fig. $\mathbf{1}$ ), the unique $R_{f}$ values ( - Tables 3 ), densitometric scan, and densitogram (- Figs. 2-4) obtained at different wavelengths from the HPTLC demonstrate that tests for alkaloids, carbohydrates, tannins, terpenoid, and phenol are positive for HACP. Photo documentation, the unique $R_{f}$ values, densitometric scan, and densitogram obtained at different wavelengths from the HPTLC can be used as a fingerprint to identify the herbal drugs HACP powder. The phytochemical tests performed to serve as a preliminary test for the standardization of the HACP formulation.

Similar findings about the presence of the compounds in the $C$. pluricaulis has been reported by several authors. ${ }^{30,31}$ Several reports on $C$. pluricaulis about central nervous system depression, anxiolytic, tranquillizing, antidepressant, antistress, neurodegenerative, antiamnesic, antioxidant, hypolipidemic, immunomodulatory, analgesic, antifungal, antibacterial, antidiabetic, antiulcer, anticatatonic, and cardiovascular activity ${ }^{32}$ have been documented. A Study on dry leaves of $C$. pluricaulis by TLC methods was found that phytochemicals like flavonoids and phenol are found. ${ }^{33}$ Dry leaf and its ash by colorimetric study was done and it was found the phytochemicals like alkaloids, carbohydrates, phenols, tannins, flavonoids, and resin were found. ${ }^{34}$ Our present phytochemical analysis of HACP also confirms similar types of compounds found in other studies. Thus, it can be used for further various clinical trials. By preserving the fundamental aspect of the Ayurvedic drug, the standardization requires a rational approach. The main obstacle in

Table 1 Results of preliminary phytochemical tests

\begin{tabular}{|l|l|}
\hline Test & Shankapushpi \\
\hline Alkaloid & + \\
\hline Carbohydrate & + \\
\hline Tannin & + \\
\hline Terpenoid & + \\
\hline Phenol & + \\
\hline
\end{tabular}

Note: $(+)$ denotes present.

Table 2 Preliminary phytochemical test results

\begin{tabular}{|c|c|c|c|}
\hline SI No & Tests & Color if positive & Shankapushpi \\
\hline \multirow[t]{5}{*}{1.} & \multicolumn{3}{|l|}{ Alkaloids } \\
\hline & Dragendrof's test & Orange precipitate & Orange precipitate \\
\hline & Wagner's test & Red precipitate & Red precipitate \\
\hline & Mayer's test & Dull-white precipitate & Dull-white precipitate \\
\hline & Hager's test & Yellow precipitate & \\
\hline \multirow[t]{3}{*}{2.} & \multicolumn{3}{|l|}{ Steroids } \\
\hline & Liebermann-Buchard test & Bluish green & Light red color \\
\hline & Salkowski's test & Bluish red to cherry red & $\begin{array}{l}\text { Cherry-red color in the chloroform and colorless in the } \\
\text { acid form }\end{array}$ \\
\hline \multirow[t]{2}{*}{3.} & \multicolumn{3}{|l|}{ Carbohydrate } \\
\hline & Molish's test & Violet ring & Violet ring \\
\hline
\end{tabular}


Table 2 (continued)

\begin{tabular}{|c|c|c|c|}
\hline SI No & Tests & Color if positive & Shankapushpi \\
\hline & Fehling's test & Brick-red precipitate & Ink-blue solution \\
\hline & Benedict's test & Red precipitate & Bluish-green solution \\
\hline \multirow[t]{2}{*}{4.} & \multicolumn{3}{|l|}{ Tannin } \\
\hline & With $\mathrm{FeCl}_{3}$ & Dark blue or green or brown & Brown \\
\hline \multirow[t]{2}{*}{5.} & \multicolumn{3}{|l|}{ Flavanoids } \\
\hline & Shinoda's test & Red to pink & Colorless solution \\
\hline \multirow[t]{2}{*}{6.} & \multicolumn{3}{|l|}{ Saponins } \\
\hline & With $\mathrm{NaHCO}_{3}$ & Stable froth & No froth \\
\hline \multirow[t]{2}{*}{7.} & \multicolumn{3}{|l|}{ Triterpenoids } \\
\hline & Tin and thionyl chloride test & Red & Light pink \\
\hline \multirow[t]{2}{*}{8.} & \multicolumn{3}{|l|}{ Coumarins } \\
\hline & With 2-N NaOH & Yellow & Light brown \\
\hline \multirow[t]{2}{*}{9.} & \multicolumn{3}{|l|}{ Phenols } \\
\hline & $\begin{array}{l}\text { With alcoholic ferric } \\
\text { chloride }\end{array}$ & Blue to black, brown & Brown \\
\hline \multirow[t]{2}{*}{10.} & \multicolumn{3}{|l|}{ Carboxylic acid } \\
\hline & With water and $\mathrm{NaHCO}_{3}$ & Brisk effervescence & No effervescence \\
\hline \multirow[t]{2}{*}{11.} & \multicolumn{3}{|l|}{ Resin } \\
\hline & With aqueous acetone & Turbidity & No turbidity \\
\hline \multirow[t]{2}{*}{12.} & \multicolumn{3}{|l|}{ Quinone } \\
\hline & $5 \% \mathrm{NaOH}$ & Pink/purple/red & Light brown \\
\hline \multirow[t]{2}{*}{13.} & \multicolumn{3}{|l|}{ Amino acids } \\
\hline & Ninhydrine reagent & Purple color & Colorless \\
\hline
\end{tabular}

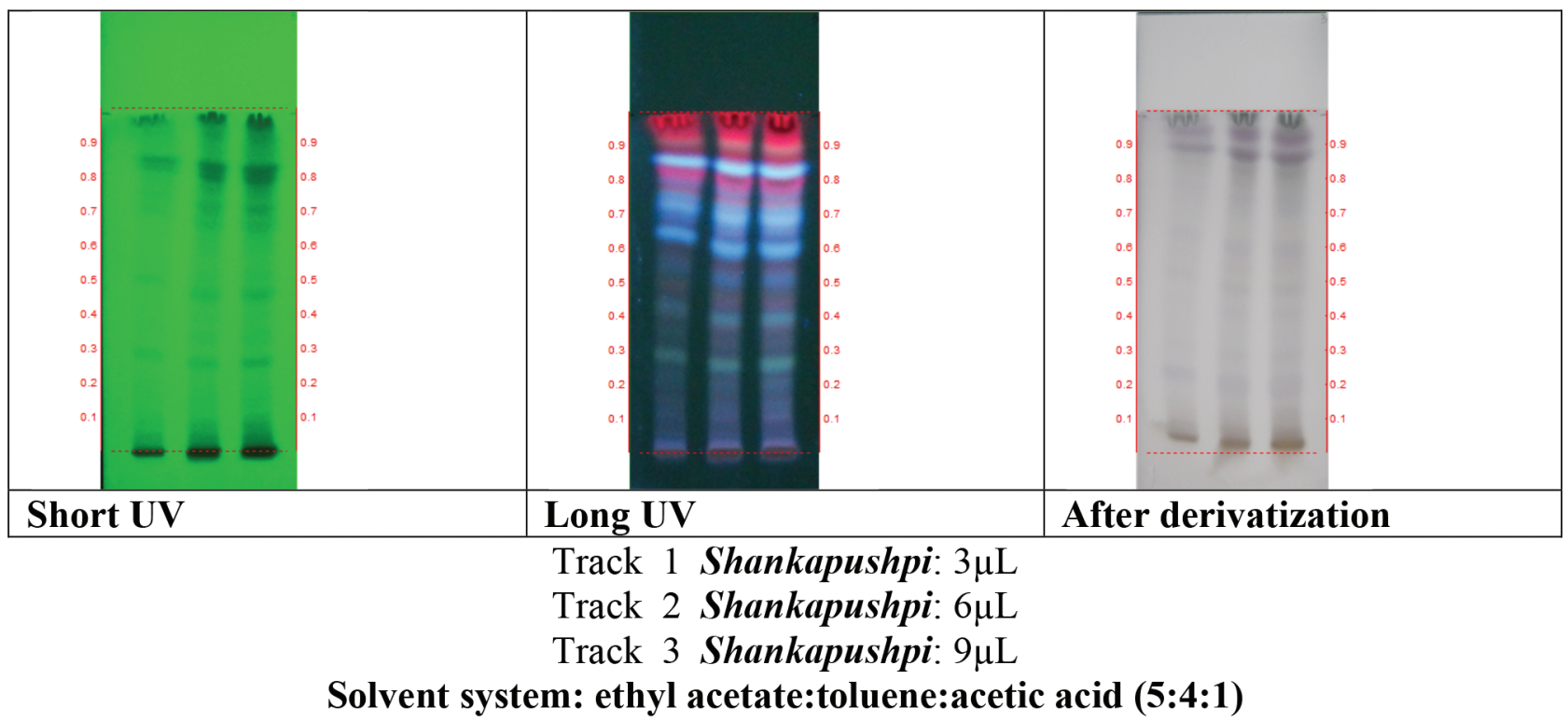

Fig. 1 HPTLC photo documentation of ethanolic extract of Shankapushpi. HPTLC, high-profile thin-layer chromatography; UV, ultraviolet. 
the standardization of the Ayurvedic drug is the identification of its biological source. Drugs from the different geographical source may vary with its active constituent and it may not be feasible to standardize drug chemically

Table 3 Rf values of samples

\begin{tabular}{|l|l|l|}
\hline Short UV & Long UV & After derivatisation \\
\hline- & 0.06 (violet) & 0.06 (L purple) \\
\hline- & 0.11 (FL violet) & 0.11 (L purple) \\
\hline- & 0.20 (FL blue) & 0.20 (L purple) \\
\hline 0.26 (D green) & 0.26 (FL green) & - \\
\hline- & - & 0.29 (L purple) \\
\hline 0.33 (L green) & 0.33 (violet) & - \\
\hline 0.38 (L green) & 0.38 (FL blue) & - \\
\hline- & - & 0.40 (L purple) \\
\hline 0.46 (D green) & 0.46 (FL pink) & - \\
\hline- & - & 0.48 (L purple) \\
\hline 0.51 (L green) & 0.51 (FL blue) & - \\
\hline- & - & 0.54 (L purple) \\
\hline- & 0.60 (FL blue) & 0.60 (L purple) \\
\hline 0.64 (D green) & - & - \\
\hline 0.69 (D green) & 0.69 (FL blue) & - \\
\hline- & 0.72 (F orange) & - \\
\hline- & 0.74 (violet) & - \\
\hline- & 0.78 (FD pink) & - \\
\hline 0.82 (D green) & 0.82 (FL blue) & 0.82 (L purple) \\
\hline- & 0.86 (FD pink) & 0.86 (D purple) \\
\hline- & 0.91 (F red) & 0.91 (D purple) \\
\hline
\end{tabular}

Abbreviations: D, dark; F, fluorescent; L, light; UV, ultraviolet.

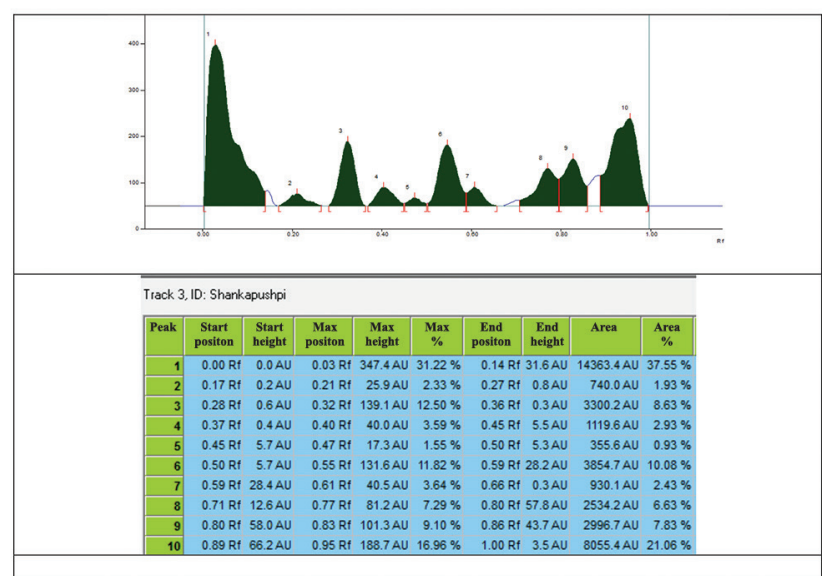

Fig. 2 Densitometric scan at $254 \mathrm{~nm}$.

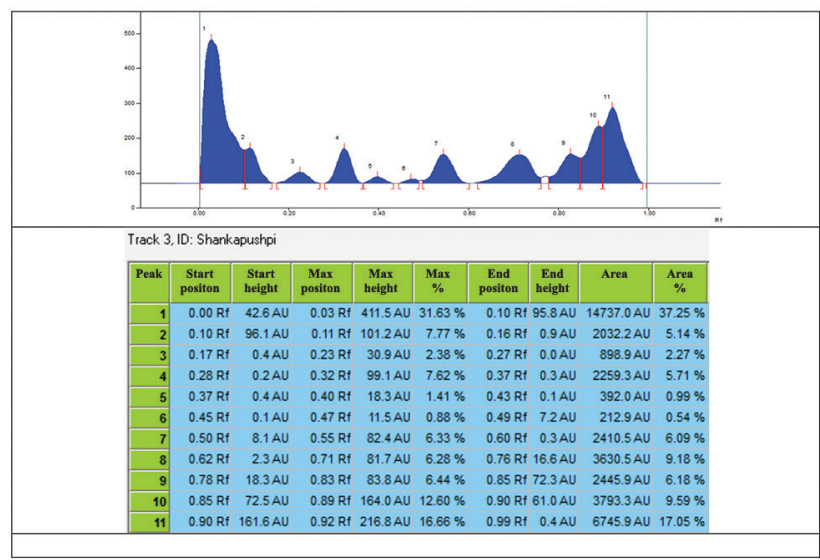

Fig. 3 Densitometric scan at $366 \mathrm{~nm}$.

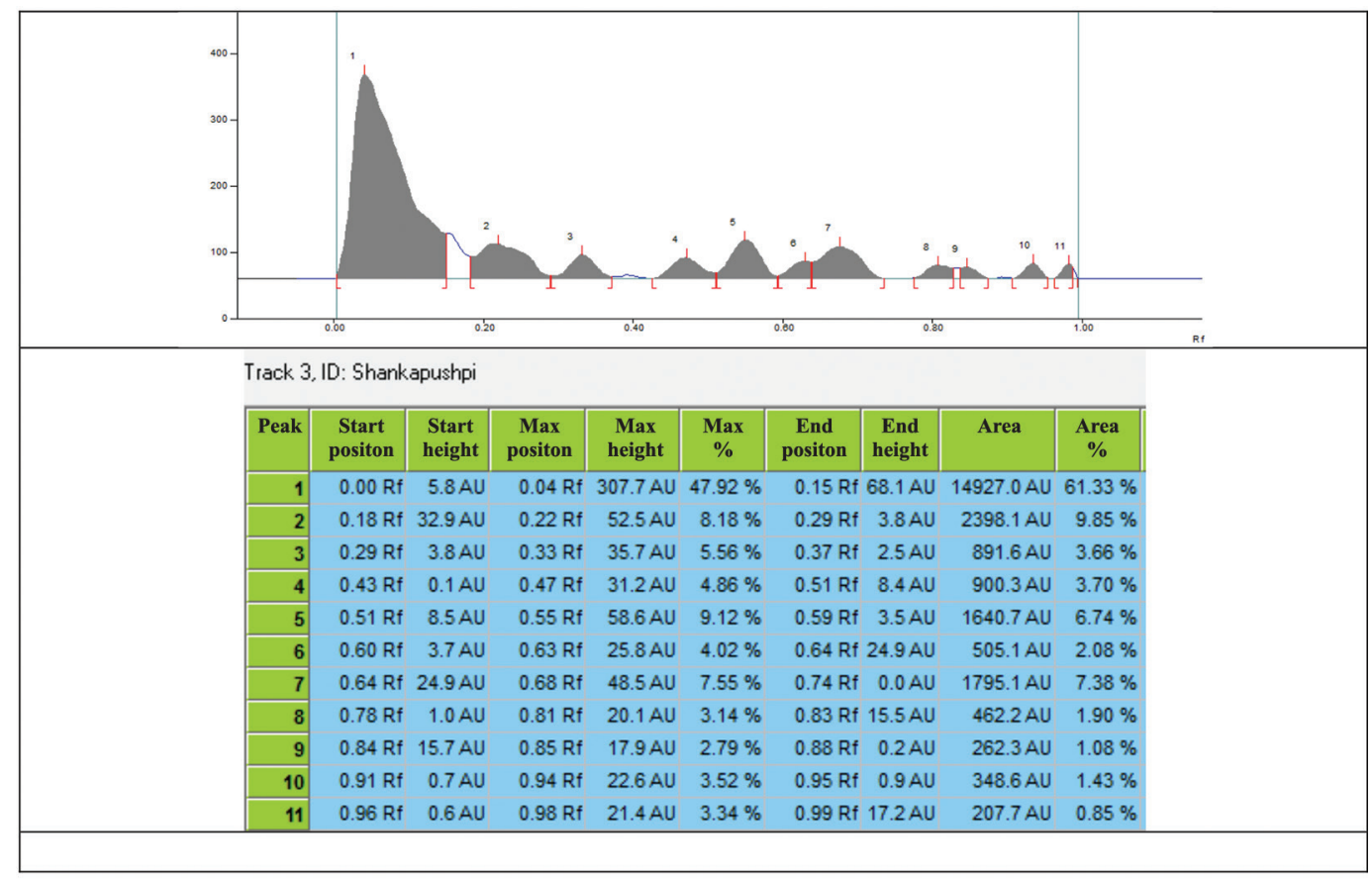

Fig. 4 Densitometric scan after derivatisation at $620 \mathrm{~nm}$. 


\section{Conclusion}

The parameters used in this work ensure the quality control of HACP. The results found through this study were rapid, reproducible, and could be used for routine monitoring of HACP. HACP is endowed with various biological properties and hence efforts have been made here to provide scientific data on the same.

\section{Conflict of Interest}

None declared.

\section{Acknowledgment}

The authors would like to thank Sri Dharmastala Ayurveda Medical College and Research Center at Udupi in Karnataka, India, for providing plant material for this study; the Management of Subbaiah Institute of Medical Sciences and Research Center at Shivamogga; and the Management of K. S. Hegde Medical Academy at Deralakatte in Mangalore.

\section{References}

1 Verma S, Sinha R, Singh V, Tanwar S, Godara M. Antibacterial activity of methanolic extract of whole plant of Convolvulus pluricaulis choisy. J Pharm Res 2011;4(12):4450-4452

2 Verma S, Singh V, Tanwar S. Pharmacognostic validation of whole plant of Convolvulus pluricaulis Choisy (Convolvulaceae) Int J Pharm Pharm Sci 2012;4(1):241-246

3 Bhowmik D, Kumar KS, Paswan S, Srivatava S, Yadav A, Dutta A. Traditional Indian herbs Convolvulus pluricaulis and its medicinal importance. J Pharmacogn Phytochem 2012;1(1):44-51

4 Singh GK, Bhandari A. Textbook of Pharmacognosy, 1st ed. New Delhi, India: CBS Publishers; 2000:193-194

5 Shalavadi MH. Physicochemical and phytochemical screening of Convolvulus pluricaulis collected from Bagalkot, Karnataka. IJGP 2018;12(03):S625-S632

6 Bharkatiya M, Goyal A, Gupta GD, Gaud RS. Memory enhancers. Indian Pharmacist 2006;5(8):32-36

7 Nordberg A, Svensson AL. Cholinesterase inhibitors in the treatment of Alzheimer's disease: a comparison of tolerability and pharmacology. Drug Saf 1998;19(6):465-480

8 Rakhit S, Basu NK. Investigations on Convulvulus pluricaulis Chois. Part II. Indian J Pharm 1958;20:357-360

9 Champatisingh D, Sahu PK, Pal A, Nanda GS. Anticataleptic and antiepileptic activity of ethanolic extract of leaves of Mucuna pruriens: A study on role of dopaminergic system in epilepsy in albino rats. Indian J Pharmacol 2011;43(2):197-199

10 WHO, Quality Control Methods for Medicinal Plant Materials. Geneva, Switzerland: World Health Organization; 1998 65-67

11 Government of India. The Ayurvedic Pharmacopeia of India. Part I. 1st ed. Vol. 1. New Delhi, India: Department of AYUSH, Ministry of Health and Family Welfare; 2001214

12 Government of India. Indian Pharmacopoeia. 1st ed. Vol. 1. New Delhi, India:: Ministry of Health and Family Welfare; 2010 10-146

13 Nayeem AA, Khatun A, Rahman MS, Rahman M. Evaluation of phytochemical and pharmacological properties of Mikania cordata (Asteraceae) leaves. J. Pharmacognosy Phytother. 2011;3(8):118-123

14 Evans WC. Trease and Evans Pharmacognosy. 14th ed. Hartcourt Brace and Company. Asia Pvt. Ltd. Singapore; 1997 226-227
15 Wagner H. Pharmazeutische Biology. 5th ed. Stuttgart, Germany. Gustav fisher Verlag; 1993

16 Neelima N, Devidas NG, Sudhakar M, Kiran VJ. A preliminary phytochemical investigation on the leaves of Solanum xanthocarpum. Int J Res Ayurveda Pharm 2011;2(3):845-850

17 Foulger $\mathrm{JH}$. The use of the Molisch (d-naphthol) reactions in the study of sugars in biological fluids. J Biol Chem 1931;92:345-353

18 Fehling H. Die quantitative Bestimmung von Zucker und Stärkmehl mittelst Kupfervitriol. [The quantitative determination of sugar and starch by means of copper sulfate]. Annalen der Chemie und Pharmacie. 1849;72(1):106-113

19 Simoni RD, Hill RL, Vaughan M. Benedict's solution, a reagent for measuring reducing sugars: the clinical chemistry of stanley R. Benedict. J. Biol. Chem. 2002;277(16):10-11

20 Nath MC, Chakravorty MK, Chowdhury SR. Liebermann-Burchard reaction for steroids. Nature 1946;157 (3978):103

21 Levine VE, Richman E. A test for cholesterol based upon the use of sulphuric acid containing selenious acid. Proc. Soc. Exper. Biol. A. Med. 1930;27(8):832-833

22 Auwal MS, Saka S, Mairiga IA, Sanda KA, Shuaibu A, Ibrahim A. Preliminary phytochemical and elemental analysis of aqueous and fractionated pod extracts of Acacia nilotica (Thorn mimosa) Vet Res Forum 2014;5(2):95-100

23 Zohra SF, Meriem B, Samira S, Muneer MA. Phytochemical screening and identification of some compounds from mallow. J Nat Prod Plant Resour. 2012;2(4):512-516

24 Usman H, Abdulrahman F, Usman A. Qualitative phytochemical screening and in vitro antimicrobial effects of methanol stem bark extract of Ficus thonningii (Moraceae) Afr J Tradit Complement Altern Med 2009;6(3):289-295

25 Pasto DJ. Johnson CR. Miller M., Experiments and Techniques in Organic Chemistry. NJ. Englewood Cliffs; 1992

26 Nidhin PS, Yaligar MG, Arun Raj GR. Koppala Narayana Sunil Kumar, Ravi M. Standardization of Harithaki (Terminalia chebula Retz.) and Trivrit (Operculina turpethum L.) churna: Two important drugs used for purgation in Ayurveda. J Pharmacogn Phytochem 2015;4(1):203-209

27 Mosettig E. The synthesis of aldehydes from carboxylic acids. Org React 2004;8:218-257

28 Ruskin RS, Kumari BV, Chitarasu T. Qualitative phytochemical and FTIR analysis of root extracts of Canthium parviflorum Lam. J Chem Pharm Sci. 2014;2:122-127

29 Geiss F. Fundamentals of Thin Layer Chromatography Planar Chromatography. Huthig: Heidelberg; 1987 854-857

30 Indian Pharmacopoeia Committee. Pharmacopoeia of India, India. 3rd ed. Ministry of Health \& Family Welfare. Controller of Publications; 1985

31 World Health Organization. The International Phamacopoeia. 3rd ed. Geneva, Switzerland: World Health Organization; 1994

32 Agarwa P, Sharma B, Fatima A, Jain SK. An update on Ayurvedic herb Convolvulus pluricaulis Choisy. Asian Pac J Trop Biomed 2014;4(3):245-252

33 Chandel U, Kharoliwal S. Phytochemical estimation of convolvulus pluricaulis. World Journal Of Pharmacy And Pharmaceutical Sciences Choisy. 2017;6(10):1074-1082

34 Prasad SB, Sharma A. Standardisation of Convolvulus pluricaulis Choisy Herbs collected from Jalandhar, Punjab. IJPPR 2016;8(8):1412-1416 